\title{
Correlation between insulin-like growth factor binding protein 3 and metastasis-associated gene 1 protein in esophageal squamous cell carcinoma
}

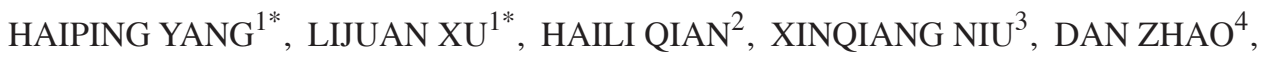 \\ ZHILONG ZHAO ${ }^{5}$, JUN WU ${ }^{1}$, JUNFENG LIU ${ }^{6}$ and YANYU WANG ${ }^{1}$
}

\begin{abstract}
${ }^{1}$ Department of Thoracic and Cardiovascular Surgery, Beijing Luhe Hospital Affiliated to Capital Medical University,
Beijing 101100; ${ }^{2}$ State Key Laboratory of Molecular Oncology, Cancer Hospital/Institute,

Chinese Academy of Medical Sciences, Beijing 100021; ${ }^{3}$ Department of Thoracic Surgery, Cixian People's Hospital, Handan, Hebei 056500; ${ }^{4}$ Department of Pathology, Beijing Chest Hospital of Capital Medical University, Beijing 101100;

${ }^{5}$ Department of Cardiothoracics, Zhongshan Hospital, Dalian University, Dalian, Liaoning 116001;

${ }^{6}$ Department of Thoracic Surgery, Fourth Hospital, Hebei Medical University, Shijiazhuang, Hebei 050011, P.R. China
\end{abstract}

Received January 28, 2015; Accepted November 25, 2015

DOI: $10.3892 / \mathrm{mmr} .2016 .5046$

\begin{abstract}
The present study aimed to investigate the correlation between insulin-like growth factor binding protein 3 (IGFBP-3) and metastasis-associated gene 1 (MTA1) protein, and the clinicopathological features and prognosis of esophageal squamous cell carcinoma (ESCC). Patients with ESCC who underwent surgical resection were enrolled in the current study, ESCC tissues and adjacent normal tissues (control) were obtained from 197 patients. The protein expression levels of IGFBP-3 and MTA1 were detected using immunohistochemistry. The results demonstrated that the expression of IGFBP-3 in ESCC tissues was significantly lower than in the adjacent normal tissues $(27.4$ vs. $40.6 \%$; $\mathrm{P}<0.05)$, and was negatively correlated with smoking status, degree of tumor differentiation and lymph node metastasis $(\mathrm{P}<0.05)$. The expression of MTA1 protein in ESCC tissues was significantly higher than that of the adjacent tissues (42.1 vs. $11.2 \%$; $\mathrm{P}<0.05)$, and was
\end{abstract}

Correspondence to: Dr Jun Wu, Department of Thoracic and Cardiovascular Surgery, Beijing Luhe Hospital Affiliated to Capital Medical University, 82 Xinhua South Road, Beijing 101100, P.R. China

E-mail: junwudoc@163.com

Dr Junfeng Liu, Department of Thoracic Surgery, Fourth Hospital, Hebei Medical University, 12 Jiankang Road, Shijiazhuang, Hebei 050011, P.R. China

E-mail: liujunfengcc@163.com

*Contributed equally

Key words: esophageal squamous cell carcinoma, insulin-like growth factor binding protein 3, metastasis-associated gene 1, immunohistochemistry, correlation positively correlated with the tumor size, extent of tumor invasion and lymph node metastasis $(\mathrm{P}<0.05)$. No association was identified between the protein expression levels of IGFBP-3 and MTA1. The protein expression levels of IGFBP-3 and MTA1 were not independent risk factors for ESCC prognosis; however, the degree of tumor invasion $(\mathrm{P}=0.02)$ and rate of lymph node metastasis $(\mathrm{P}=0.027)$ were. IGFBP-3 inhibits the proliferation and metastasis of ESCC; however, MTA1 promotes the proliferation and metastasis of ESCC. There is no interaction between IGFBP-3 and MTA1 in ESCC, and they are not independent risk factors for ESCC prognosis.

\section{Introduction}

Esophageal squamous cell carcinoma (ESCC) is one of the ten most common types of malignancy worldwide, and is associated with a poor prognosis (1). In China, ESCC has fourth highest rate of cancer-related mortality (2). The overall 5 -year survival rate is $<30 \%$, and the high recurrence rate is the predominant reason for poor quality of life and mortality in patients with ESCC $(3,4)$. Therefore, investigation into the mechanism underlying the recurrence and metastasis of ESCC is of clinical significance for improving the prognosis of these patients. Increased expression levels of metastasis-associated 1 gene (MTA1) are positively correlated with the invasion and metastasis of a variety of types of malignant tumor (5). Toh et al (6) observed that the expression level of MTA1 in ESCC is associated with deacetylase activity of the H4 histone, and that the invasion and lymph node metastasis of tumor cells with high expression levels of MTA1 mRNA are significantly increased.

The insulin-like growth factor (IGF) signaling pathway is important for the proliferation, differentiation and apoptosis of cells, among which IGF-1 and IGF binding protein 3 (IGFBP-3) are key in cell growth and tumor formation (7). 
Rajah et al (8) demonstrated that by blocking the binding of IGFs to their receptors, IGFBP-3 inhibits the activity of IGFs and induces apoptosis, indicating a protective effect. A number of epidemiological studies have demonstrated that high levels of circulating IGF-1 and low levels of IGFBP-1 are associated with increased risk of several common cancers, including breast (9), prostate (10), lung (11) and colorectal (12).

The association of MTAl and IGFBP-3 expression levels with the clinical pathology and prognosis of ESCC is rarely evaluated, and whether the expression levels of these two factors are associated with ESCC remains to be elucidated. The present study investigated the correlation of IGFBP-3 and MTA1 protein expression and the clinicopathological features and prognosis of 197 ESCC patients, with the aim of providing an objective basis for the diagnosis and treatment of ESCC.

\section{Subjects and methods}

Subjects. ESCC patients (148 males and 49 females; age, 41-77 years; mean age, 59.8 years) who underwent ESCC resection in the Department of Thoracic and Cardiovascular Surgery, Beijing Luhe Hospital Affiliated to Capital Medical University (Beijing, China) or Department of Thoracic Surgery, Cixian People's Hospital (Handan, China) between October 2008 and June 2010 were enrolled in the present study. All patients were diagnosed with ESCC by preoperative biopsy, had surgical indications and no surgical contraindications. They did not receive preoperative adjuvant therapies, such as radiotherapy or chemotherapy, and had no serious perioperative complications. The pathological specimens embedded in paraffin were preserved well and the medical records were complete. The present study was approved by the Ethics Committee of Beijing Luhe Hospital Affiliated to Capital Medical University (Beijing, China) and informed consent was obtained from all patients.

Grouping of paraffin specimens and detection of IGFBP-3 and MTA1 expression. The paraffin specimens were divided into an ESCC group and control group, which included ESCC tissues (197 samples) and adjacent normal tissues $(>5 \mathrm{~cm}$ away from the tumor margin; 197 samples), respectively. The expression levels of IGFBP-3 and MTA1 protein were detected by immunohistochemistry according to previously described methods $(13,14)$. Primary antibodies used included rabbit anti-human polyclonal antibody against IGFBP-3 (Wuhan Boster Biological Technology, Ltd., Wuhan, China; cat. no. BA2162; dilution, 1:100) and goat anti-human polyclonal antibody against MTA1 (Santa Cruz Biotechnology, Inc., TX, USA; cat. no. sc-9446; dilution, 1:100). Secondary antibodies including goat anti-rabbit immunoglobulin $\mathrm{G}(\mathrm{IgG})$ conjugated to horseradish peroxidase (HRP; cat. no. ZB-2301; dilution, 1:2,000) and rabbit anti-goat IgG-HRP (cat. no. ZB-2306; dilution, 1:2,000) were purchased from Beijing Zhongshan Golden Bridge Biotechnology Co., Ltd., Beijing, China).

Pathological grading. According to the 7th edition of the ESCC staging system (15), there were 35, 51 and 111 cases with phase I, II and III ESCC, respectively. In total, 35 cases were well-differentiated, 123 cases were moderately-differentiated, and 39 cases were poorly-differentiated. Tumor size $\leq 3 \mathrm{~cm}$ was observed in 43 cases, while tumor size $>3 \mathrm{~cm}$ was observed in 154 cases.

Criteria to judge results. The stained slides were evaluated by two independent pathologists. The proportion of cells with positive brown staining for MTA1 and IGFBP-3 was observed. The positive-cell scoring was as follows: $<5 \%, 0$ points; $5-25 \%$, 1 point; $26-50 \%, 2$ points; $51-75 \%, 3$ points; and $>75 \%, 4$ points. The staining intensity with MTA1 and IGFBP-3 antibodies was scored was as follows: Minimal staining similar to the background, 0 points; lightly stained, more than the background and pale yellow, 1 point; moderately stained, markedly more than the background and a brown-yellow, 2 points; and clearly stained a dark brown-yellow or tan, 3 points. The total scoring was as follows: Total score $=$ number of positive cells $\mathrm{x}$ staining intensity. Total score $\geq 5$ indicated a positive result, and $<5$ indicated a negative result. The nucleus and cytoplasm were observed to perform the scoring and statistical analysis. All the sections were judged by two pathologists blinded to the groupings and the inconsistencies were negotiated to reach a consensus.

Follow up. All the patients were successfully discharged, and follow up was performed once every three months for the first 2 years and subsequently once every 6 months. Follow-up included physical examination, chest X-ray, biochemical analysis (squamous cell carcinoma antigen, carbohydrate antigen (CA)-125, $\alpha$-fetal protein, cancer embryo antigen, CA-199, CA-153, ferritin), computed tomography, ultrasound and gastroscopy. The postoperative tumor recurrence and metastasis were diagnosed according to the patients' imaging and histological findings, and the locations and times of recurrence and metastasis were recorded. The disease-free survival period referred to the period starting from the date of surgery to that of tumor recurrence or mortality as a result of non-cancer-associated disease. The overall survival period refers to the period starting from the date of surgery to mortality or to the follow-up deadline. The follow-up deadline of the present study was June 30, 2013, with a median follow-up time of 12 months (2-56 months). The follow-up data was obtained from outpatient and telephone reviewing.

Statistical analysis. SPSS 16.0 statistical software (SPSS, Inc., Chicago, IL, USA) was used for data analysis. The association between positive staining for IGFBP-3 and MTA1, and the clinical pathological characteristics were analyzed with a $\chi^{2}$ test. The Kaplan-Meier life-table method was performed for the survival analysis and log-rank test was used to determine the survival difference. The multivariate analysis used the COX regression analysis to determine the independent risk factors of prognosis. $\mathrm{P}<0.05$ was considered to indicate a statistically significant difference.

\section{Results}

Expression levels of IGFBP-3 and MTA1 protein in ESCC and adjacent tissues. Positive staining for IGFBP-3 was predominantly localized to the cytoplasm. Among the 197 ESCC cases, 54 cancer tissue samples $(27.4 \%)$ exhibited positive expression of IGFBP-3, while 80 adjacent tissue samples (40.6\%) exhibited expression of IGFBP-3. The intergroup comparison 
Table I. Expression of IGFBP-3 and MTA1 protein in cancer tissues and adjacent normal tissues.

\begin{tabular}{|c|c|c|c|c|c|c|}
\hline \multirow[b]{2}{*}{ Tissue } & \multicolumn{2}{|c|}{ IGFBP-3 (no. of cases) } & \multirow[b]{2}{*}{ P-value } & \multicolumn{2}{|c|}{ MTA1 (no. of cases) } & \multirow[b]{2}{*}{ P-value } \\
\hline & Negative & Positive & & Negative & Positive & \\
\hline Cancer & 143 & 54 & 0.008 & 114 & 83 & 0.001 \\
\hline Adjacent normal & 117 & 80 & & 175 & 22 & \\
\hline
\end{tabular}

IGFBP-3; insulin-like growth factor binding protein 3; MTA1, metastasis-associated gene 1.

Table II. Correlation between IGFBP-3 expression and clinicopathological characteristics in 197 patients with esophageal squamous cell carcinoma.

\begin{tabular}{|c|c|c|c|c|}
\hline \multirow[b]{2}{*}{ Parameter } & \multirow[b]{2}{*}{ No. of cases } & \multicolumn{2}{|c|}{ IGFBP-3, no. of cases $(\%)$} & \multirow[b]{2}{*}{ P-value } \\
\hline & & Negative & Positive & \\
\hline Gender & & & & $<0.05$ \\
\hline Male & 148 & $101(68.2)$ & $47(31.8)$ & \\
\hline Female & 49 & $42(85.7)$ & $7(14.3)$ & \\
\hline Age (years) & & & & $>0.05$ \\
\hline$<59$ & 93 & 67 (72.0) & $26(28.0)$ & \\
\hline$\geq 59$ & 104 & $76(73.1)$ & $28(26.9)$ & \\
\hline Smoking status & & & & $<0.05$ \\
\hline$<30$ pack-years & 103 & $67(65.0)$ & $36(35.0)$ & \\
\hline$\geq 30$ pack-years & 94 & $76(80.9)$ & $18(19.1)$ & \\
\hline Family history & & & & $<0.05$ \\
\hline No cancer & 153 & $105(68.6)$ & 48 (31.4) & \\
\hline With cancer & 44 & $38(86.4)$ & $6(13.6)$ & \\
\hline Tumor size $(\mathrm{cm})$ & & & & $>0.05$ \\
\hline$\leq 3$ & 43 & 33 (76.7) & $10(23.3)$ & \\
\hline$>3$ & 154 & $110(71.4)$ & $44(28.6)$ & \\
\hline WHO grade & & & & $<0.05$ \\
\hline G1 & 35 & 17 (48.6) & 18 (51.4) & \\
\hline G2 & 123 & 93 (75.6) & $30(24.4)$ & \\
\hline G3 & 39 & $33(84.6)$ & $6(15.4)$ & \\
\hline T status & & & & $>0.05$ \\
\hline $\mathrm{T} 1$ & 29 & $23(79.3)$ & $6(20.7)$ & \\
\hline $\mathrm{T} 2$ & 57 & 37 (64.9) & $20(35.1)$ & \\
\hline T3 & 107 & $80(74.7)$ & $27(25.2)$ & \\
\hline $\mathrm{T} 4$ & 4 & $3(75.0)$ & $1(25.0)$ & \\
\hline $\mathrm{N}$ status & & & & $<0.05$ \\
\hline N0 & 109 & $69(63.3)$ & $40(36.7)$ & \\
\hline N1 & 88 & $74(84.1)$ & $14(15.9$ & \\
\hline Survival status & & & & $>0.05$ \\
\hline Alive & 71 & 53 (74.6) & $18(25.4)$ & \\
\hline Deceased & 126 & $90(71.4)$ & 36 (28.6) & \\
\hline
\end{tabular}

IGFBP-3; insulin-like growth factor binding protein 3; WHO, World Health Organisation; T, tumor invasion degree; N; lymph node metastasis rate.

indicated a statistically significant difference $(\mathrm{P}<0.05$; Table I; Fig. 1A and B).
The staining of MTA1 protein was predominantly localized in the nucleus. Among the 197 ESCC cases, 83 cancer 
Table III. Correlation between MTA1 protein expression and clinicopathological characteristics in 197 patients with esophageal squamous cell carcinoma.

\begin{tabular}{|c|c|c|c|c|}
\hline \multirow[b]{2}{*}{ Parameter } & \multirow[b]{2}{*}{ Case } & \multicolumn{2}{|c|}{ MTA1 protein, no. of cases (\%) } & \multirow[b]{2}{*}{ P-value } \\
\hline & & Negative & Positive & \\
\hline Gender & & & & $>0.05$ \\
\hline Male & 148 & $85(57.4)$ & $63(42.6)$ & \\
\hline Female & 49 & $29(59.2)$ & $20(40.8)$ & \\
\hline Age (years) & & & & $>0.05$ \\
\hline$<59$ & 93 & $55(59.1)$ & $38(40.9)$ & \\
\hline$\geq 59$ & 104 & $59(56.7)$ & $45(43.3)$ & \\
\hline Smoking status & & & & $>0.05$ \\
\hline$<30$ pack-year & 103 & $61(59.2)$ & $42(40.8)$ & \\
\hline$\geq 30$ pack-year & 94 & $53(56.4)$ & $41(43.6)$ & \\
\hline Family history & & & & $<0.05$ \\
\hline No cancer & 153 & $81(52.9)$ & $72(47.1)$ & \\
\hline With cancer & 44 & $33(75.0)$ & $11(25.0)$ & \\
\hline Tumor size $(\mathrm{cm})$ & & & & $<0.05$ \\
\hline$\leq 3$ & 43 & $32(74.4)$ & $11(25.6)$ & \\
\hline$>3$ & 154 & $82(53.2)$ & $72(46.8)$ & \\
\hline WHO grade & & & & $>0.05$ \\
\hline G1 & 35 & $18(51.4)$ & $17(48.6)$ & \\
\hline G2 & 123 & $75(61.0)$ & $48(39.0)$ & \\
\hline G3 & 39 & $21(53.8)$ & $18(46.2)$ & \\
\hline T status & & & & $<0.05$ \\
\hline $\mathrm{T} 1$ & 29 & $21(72.4)$ & $8(27.6)$ & \\
\hline $\mathrm{T} 2$ & 57 & $37(64.9)$ & $20(35.1)$ & \\
\hline T3 & 107 & $54(50.5)$ & $53(49.5)$ & \\
\hline $\mathrm{T} 4$ & 4 & $2(50.0)$ & $2(50.0)$ & \\
\hline $\mathrm{N}$ status & & & & $<0.05$ \\
\hline No & 109 & $71(65.1)$ & $38(34.9)$ & \\
\hline N1 & 88 & $43(48.9)$ & $45(51.1)$ & \\
\hline Survival status & & & & $>0.05$ \\
\hline Alive & 71 & $41(57.7)$ & $30(42.3)$ & \\
\hline Deceased & 126 & $73(57.9)$ & $53(42.1)$ & \\
\hline
\end{tabular}

MTA1, metastasis-associated gene 1; WHO, World Health Organisation; T, tumor invasion degree; N; lymph node metastasis rate.

tissue samples (42.1\%) exhibited positive expression of MTA1, while 22 adjacent tissue samples (11.2\%) exhibited positive expression of MTA1 protein. The intergroup comparison indicated a statistically significant difference $(\mathrm{P}<0.05$; Table I; Fig. 1C and D).

Correlation between IGFBP-3 and MTA1 protein expression levels and clinicopathological characteristics. The expression of IGFBP-3 differed significantly difference between male and female patients and between patients with and without tumor family history $(\mathrm{P}<0.05)$, and was negatively correlated with the smoking status, degree of tumor differentiation and lymph node metastasis $(\mathrm{P}<0.05)$, but was not correlated with age, tumor size, extent of tumor invasion or survival status $(\mathrm{P}>0.05$, $\chi^{2}$ test; Table II).
The expression of MTA1 protein was positively correlated with the tumor size, degree of tumor invasion and lymph node metastasis $(\mathrm{P}<0.05)$, and negatively correlated with a family history of cancer $(\mathrm{P}<0.05)$. It was not correlated with gender, age, the smoking status, degree of tumor differentiation or survival status $\left(\mathrm{P}>0.05, \chi^{2}\right.$ test; Table III).

Correlation between IGFBP-3 and MTA1 protein expression. Positive expression of MTA1 and IGFBP-3 was observed in 23 cases, while 83 cases were negative for both MTA1 and IGFBP-3 protein expression. The $\chi^{2}$ test indicated that there was no association between IGFBP-3 and MTA1 (P>0.05; Table IV).

Correlation of IGFBP-3 and MTA1 protein expression with prognosis of patients with ESCC. Based on the follow-up 
Table IV. Correlation between IGFBP-3 and MTA1 protein expression.

\begin{tabular}{lccccr}
\hline & \multicolumn{3}{c}{ IGFBP-3 } & & \\
\cline { 2 - 5 } MTA1 & Negative & Positive & Total & $\chi^{2}$ & P-value \\
\hline Negative & 83 & 31 & 114 & & \\
Positive & 60 & 23 & 83 & 0.936 & $>0.05$ \\
Total & 143 & 54 & 197 & & \\
\hline
\end{tabular}

IGFBP-3; insulin-like growth factor binding protein 3; MTA1, metastasis-associated gene 1.

A

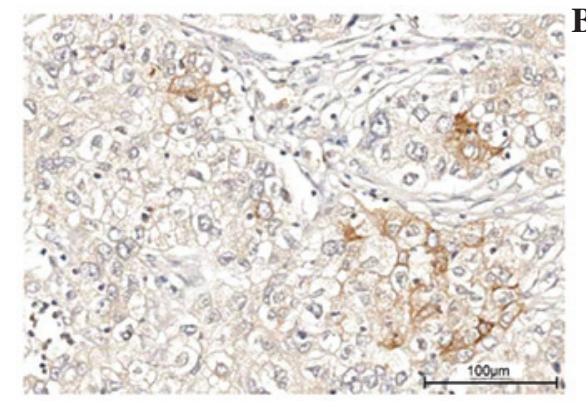

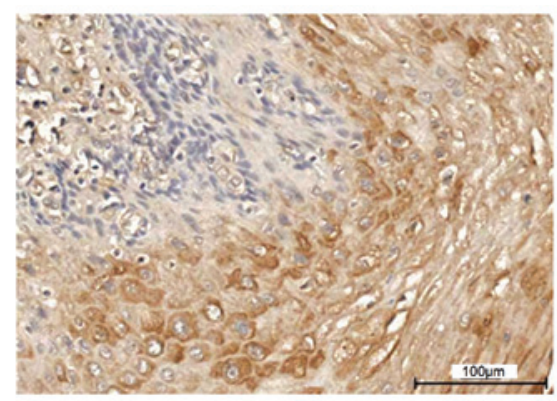

D

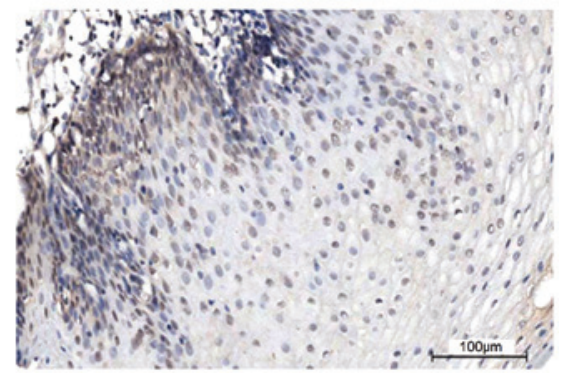

Figure 1. Immunohistochemistry to identify the expression of MTA1 and IGFBP-3. (A) Low expression of IGFBP-3 in ESCC tissue samples and (B) strong expression in adjacent normal tissue samples. Positive staining is located in the cytoplasm. (C) High expression of MTA1 in ESCC tissue and (D) low expression in adjacent normal tissues. Positive staining is located in the nucleus. Magnification, x200.

data of 197 ESCC cases, the Kaplan-Meier survival curve analysis indicated that the 3-year survival rate of all patients was $36.04 \%$ (Fig. 2). The 3 -year survival rates of the patients with positive and negative expression of IGFBP-3 and MTA1 protein indicated no significant difference by the Log-rank test $(\mathrm{P}=0.874$ and $\mathrm{P}=0.942$, respectively; Fig. 3). The multivariate analysis of COX regression demonstrated that the expression of IGFBP-3 and MTA1 were not independent risk factors of ESCC, while the tumor invasion degree $(\mathrm{P}=0.020)$ and lymph node metastasis rate $(\mathrm{P}=0.027)$ were $($ Table $\mathrm{V})$.

\section{Discussion}

The occurrence, development and prognosis of ESCC are the result of multiple factors, including genetics and environment. Various genes that are associated with tumorigenesis, invasion and metastasis have been identified and cloned. The ESCC-associated genes include alcohol dehydrogenase, cytochrome P450, family 1, member A1, IGF-1 and MTA1, which provide a theoretical basis for improvements in the diagnosis, treatment and prognosis of ESCC (16). The IGF system includes IGF-1 and IGF-2, and their receptors IGF-1R and IGF-2R.

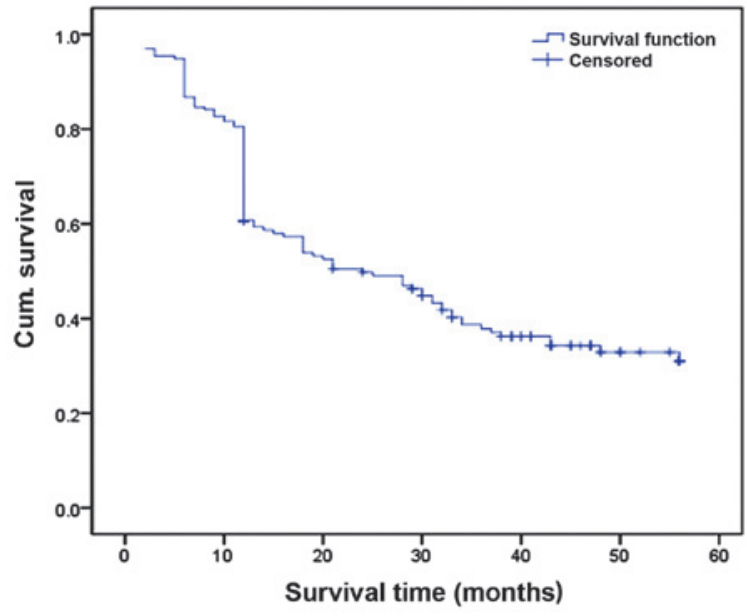

Figure 2. Kaplan-Meier survival curve of 197 patients with ESCC. The 3-year survival rate was $36.04 \%$.

There are at least seven types of IGFBP (IGFBP1-7). IGF-1R is the most active, and the combination of IGF-1R and IGF-1 promotes mitosis, cell transformation, anti-apoptosis, which 
Table V. Results of COX multivariate regression analysis.

\begin{tabular}{|c|c|c|c|c|c|}
\hline Parameter & $\mathrm{B}$ & SE & Wald & P-value & $95 \% \mathrm{CI}$ for $\mathrm{HR}$ \\
\hline Gender & 0.151 & 0.314 & 0.232 & 0.630 & $1.163(0.628-2.154)$ \\
\hline Age & 0.006 & 0.013 & 0.196 & 0.658 & $1.006(0.980-1.033)$ \\
\hline Smoking status & 0.237 & 0.262 & 0.820 & 0.365 & $1.267(0.759-2.117)$ \\
\hline Grade & -0.650 & 0.165 & 0.154 & 0.695 & $0.938(0.679-1.294)$ \\
\hline $\mathrm{T}$ & 0.349 & 0.150 & 5.413 & 0.020 & $1.418(1.057-1.902)$ \\
\hline $\mathrm{N}$ & 0.461 & 0.208 & 4.919 & 0.027 & $1.586(1.055-2.383)$ \\
\hline Tumor size & 0.306 & 0.290 & 1.109 & 0.292 & $1.358(0.768-2.399)$ \\
\hline IGFBP-3 & -0.128 & 0.221 & 0.335 & 0.563 & $0.88(0.570-1.358)$ \\
\hline MTA1 & -0.166 & 0.195 & 0.728 & 0.394 & $0.847(0.578-1.241)$ \\
\hline
\end{tabular}

B, regression coefficient; SE, standard error; wald, wald value; CI, confidence interval; HR, hazard ratio; IGFBP-3; insulin-like growth factor binding protein 3; MTA1, metastasis-associated gene 1; T, tumor invasion degree; N; lymph node metastasis rate.
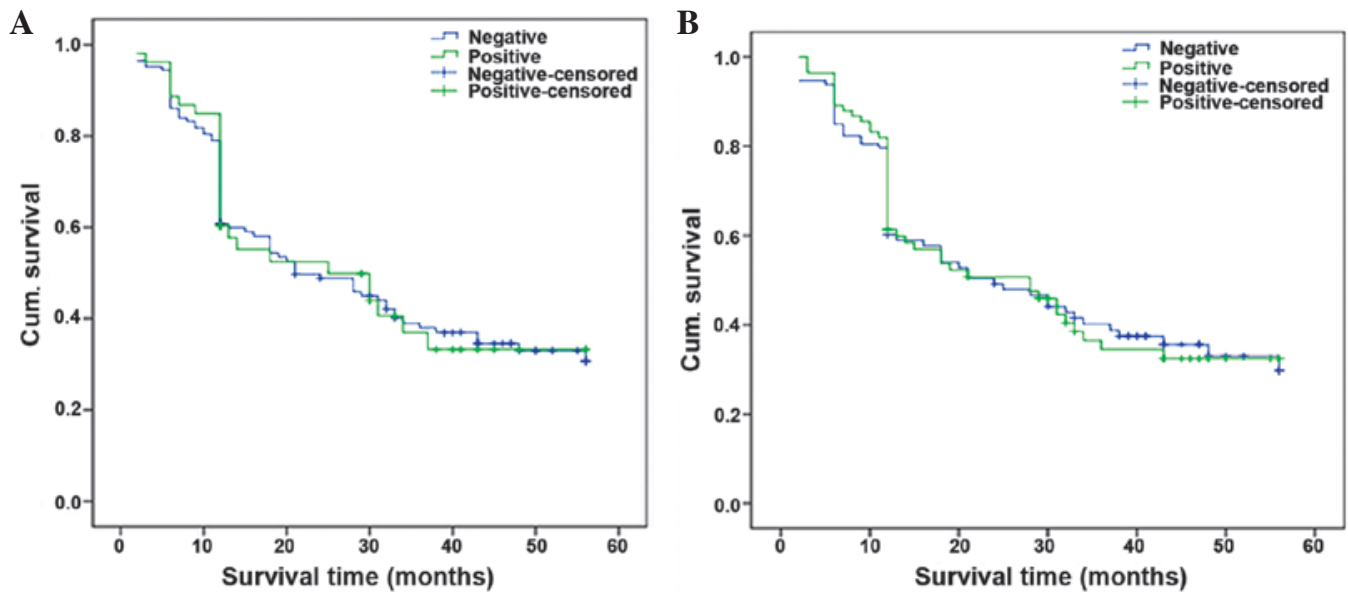

Figure 3. (A) Kaplan-Meier curve indicates that the 3-year survival of patients with IGFBP-3 expression was not improved compared with patients not expressing IGFBP-3 (cytoplasm total score $\geq 5$, positive; plasma total score $<5$, negative). (B) Kaplan-Meier curve indicates that the 3 -year survival of patients with MTA1 expression was not improved compared with patients not expressing MTA1 (nuclear total score total score $\geq 5$, positive; plasma total score $<5$, negative).

are insulin-like biological functions. The role of IGFBPs is to act as the IGF carrier in the blood circulation, and IGFBP-3 predominates. IGFBP-3 binds with $>80 \%$ of the IGF-1 in the circulation, which transports IGF-1 to the reaction site, and protects IGF-1 from degradation by proteases. Thus, IGFBP-3 is important in the regulation of the concentration of IGF-1 and inhibits or enhances IGF-1 function. Therefore, IGFBP-3 and IGF-1R are key regulatory aspects in the IGF signaling pathway (17).

IGFBP-3 may also interact with other proteins and, thus, be important in the inhibition of proliferation and promotion of apoptosis in various cells in a non-IGF-1-dependent manner, therefore, IGFBP-3 exhibits a dual regulatory role in the IGF family (18). IGFBP-3 translocates into the nucleus and directly or indirectly interacts with the intranuclear growth inhibition and apoptosis genes, affecting cellular gene expression and inducing apoptosis (19). Overexpression of IGFBP-3 may increase the cellular apoptosis $(20,21)$, suggesting that it may act as a tumor suppressor. Abnormal methylation and gene silencing of the IGFBP-3 promoter has been observed in different types of cancer, and its abnormal expression or dysfunction has been associated with cancer development (22-24).

It has been reported that the expression levels of IGFBP-3 in lung cancer (25), hepatocellular carcinoma (26), ovarian cancer (27) and prostate cancer (28) are reduced. Tas et al $(29,30)$ observed that the serum IGFBP-3 concentration did not predict the prognosis of breast and ovarian cancer. Another previous study indicated that high expression of IGFBP-3 is significantly associated with the recurrence of prostate cancer (31). In addition, Kim et al (32) investigated 191 cases of lung cancer and observed that IGFBP-3 was not significantly correlated with the patients' clinicopathological changes. Rohrmann et al (33) observed that low concentrations of serum IGFBP-3 did not increase the risk of pancreatic cancer. These contradictory studies may be due to the protective effect of increased expression of IGFBP-3, which inhibits cell proliferation and induces apoptosis. However, under different experimental conditions, IGFBP-3 may stimulate cell proliferation in an IGF signaling pathway-dependent or independent manner (34). In certain cases, IGFBP-3 exerts positive effects toward cell growth (35). The expression levels 
of IGFBP-3 in ESCC are uncertain. The present study uses the immunohistochemical method to evaluate the IGFBP-3 expression in ESCC and its impact on the prognosis of ESCC patients. The results demonstrate that IGFBP-3 is expressed predominantly in the cytoplasm, and the positive expression of IGFBP-3 in the ESCC tissue samples is significantly lower than that in the adjacent tissue samples (27.4 vs. $40.6 \%$; $\mathrm{P}<0.05)$. The low expression levels of IGFBP-3 in the ESCC tissues may be due to IGFBP-3 as a downstream gene of p53, and mutated p53 loses the ability to activate IGFBP-3 via its transcriptional signaling pathway (36), thus the functions of IGFBP-3 that inhibit tumor cell proliferation and apoptosis via the IGF-1-dependent signaling pathway are blocked (37). This may also be associated with the reduction of apoptosis induced by IGFBP-3 via the p53 signaling pathway (8).

The present study also demonstrates that the positive expression of IGFBP-3 in ESCC is associated with gender, smoking status and family history of cancer, which is consistent with esophageal cancer epidemiology. The expression of IGFBP-3 is negatively correlated with the degree of ESCC differentiation and lymph node metastasis, tumors of different grades (G1, G2 and G3). The positive expression rates of IGFBP-3 were 51.4, 24.4 and $15.4 \%$, respectively, and the IGFBP-3 expression in patients with non-lymph node metastasis was significantly higher than those with lymph node metastasis (36.7 vs. $15.9 \%$ ). This may be associated with the anti-angiogenic and anti-metastatic roles of IGFBP-3 $(38,39)$. In the present study, IGFBP-3 staining was observed inside the nuclei of ESCC cells, although it is markedly weaker compared with in the cytoplasm. This may be due to IGFBP-3 expression inside the nuclei directly or indirectly inducing the apoptosis of cancer cells, thus inhibiting the tumor cell growth (40), however, this requires further elucidation.

MTA1 is upregulated during tumor metastasis, as observed by Toh et al in 1994 (41). The human MTA1 gene is located on $14 q 32.3$ (42), with full-length cDNA of 2,756 bp. The encoded protein has 703 amino acid residues, and the product of this gene is a component of the nuclear remodeling and deacetylation complex, which regulates gene transcription by affecting the chromatin state (5). There is a low level of MTA1 in normal body tissues, including the heart, kidney, lung, liver, while in a variety of tumor tissues, such as from liver, lung and ovarian cancer, it is highly expressed. Toh et al (6) observed that MTA1 expression in ESCC is associated with the activity of $\mathrm{H} 4$ histone deacetylase. As tumor suppressor genes, including p53, p21 and retinoblastoma, are regulated by histone acetylation (43), the invasion and lymph node metastasis of tumor cells that have high MTA1 mRNA expression levels are significantly increased.

Results of the present study demonstrate that the MTA1 protein is predominantly expressed in the nucleus. In ESCC tissue samples, the MTA1 protein expression level was significantly higher than in the control samples (42.1 vs. 11.2\%; $\mathrm{P}<0.05)$, while its expression was not associated with the gender, age, smoking status or degree of tumor tissue differentiation, while in the patients with no family history of cancer the MTA1 expression is as high as $47.1 \%$. Furthermore, MTAl expression was positively correlated with tumor size, extent of cancer tissue invasion and lymph node metastasis. In the patients with tumors $>3 \mathrm{~cm}$, the percentage of patients that expressed MTA1 was $46.8 \%$, while in the patients with tumors $\leq 3 \mathrm{~cm}$, the percentage of patients expressing MTA1 was $25.6 \%$. MTA1 expression rates in different stages of invasive cancer (T1, T2 and T3) were 27.6, 35.1 and 49.5\%, respectively. The expression of MTA1 in patients with lymph node metastasis was significantly higher than those without lymph node metastasis ( 51.1 vs. $34.9 \%$; $\mathrm{P}<0.05)$. This may be due to the involvement of MTA1 in changing the assembly of the cytokeratin filament system and location of cytoskeletal proteins, thus increasing the cellular invasion and metastasis (44). In the present study, IGFBP-3 and MTA1 exhibited no interaction in the clinicopathological features of ESCC. They were not identified to be correlated with the prognosis of ESCC, and they were not independent risk factors in the prognosis of ESCC; however, the extent of tumor invasion and the rate of lymph node metastasis are the independent risk factors in ESCC prognosis. No significant correlation was identified between the protein expression of IGFBP-3 and tumor size, positive expression of MTA1 and the degree of tumor tissue differentiation, or expression of the two proteins and prognosis. This may be affected by certain cases in the present study coming from the ESCC-high-incidence region (Cixian, China). The patients in this geographical area undergo regular screening and earlier treatment due to the high prevalence of ESCC. Certain cases were also from Beijing, China, which has a low incidence of ESCC and a poorer screening program, thus, these patients usually only seek medical help when clinical symptoms appear and their staging tends to be higher.

The present study has certain limitations. First, the samples are from different regions. A number of the cases were obtained from a region with high-incidence of ESCC, which may have affected the current study. Second, reverse transcription-polymerase chain reaction or western blot analysis were not performed to validate the immunohistochemical results, these should be conducted in the future. Third, the follow-up period was short and should be increased in future research.

In conclusion, low expression levels of IGFBP-3 may be a risk factor of ESCC, and high expression levels of MTAl are closely associated with the invasion and metastasis of ESCC. The detection of IGFBP-3 and MTAl may have important clinical implications for the diagnosis, treatment and prognosis of ESCC.

\section{References}

1. Jemal A, Bray F, Center MM, Ferlay J, Ward E and Forman D: Global cancer statistics. CA Cancer J Clin 61: 69-90, 2011.

2. Suntharalingam M: Definitive chemoradiation in the management of locally advanced esophageal cancer. Semin Radiat Oncol 17: 22-28, 2007.

3. Rohatgi PR, Swisher SG, Correa AM, Wu TT, Liao Z, Komaki R, Walsh G, Vaporciyan A, Lynch PM, Rice DC, et al: Failure patterns correlate with the proportion of residual carcinoma after preoperative chemoradiotherapy for carcinoma of the esophagus. Cancer 104: 1349-1355, 2005.

4. Di Fiore F, Lecleire S, Rigal O, Galais MP, Ben Soussan E, David I, Paillot B, Jacob JH and Michel P: Predictive factors of survival in patients treated with definitive chemoradiotherapy for squamous cell esophageal carcinoma. World J Gastroenterol 12: 4185-4190, 2006.

5. Nicolson GL, Nawa A, Toh Y, Taniguchi S, Nishimori K and Moustafa A: Tumor metastasis-associated human MTA1 gene and its MTA1 protein product: Role in epithelial cancer cell invasion, proliferation and nuclear regulation. Clin Exp Metastasis 20: 19-24, 2003. 
6. Toh Y, Ohga T, Endo K, Adachi E, Kusumoto H, Haraguchi M, Okamura T and Nicolson GL: Expression of the metastasis-associated MTA1 protein and its relationship to deacetylation of the histone $\mathrm{H} 4$ in esophageal squamous cell carcinomas. Int $\mathbf{J}$ Cancer 110: 362-367, 2004

7. Holdaway IM, Mason BH, Lethaby AE, Singh V, Harvey VJ, Thompson PI and Evans BD: Serum insulin-like growth factor-I and insulin-like growth factor binding protein-3 following chemotherapy for advanced breast cancer. ANZ J Surg 73: 905-908, 2003

8. Rajah R, Valentinis B and Cohen P: Insulin-like growth factor (IGF)-binding protein-3 induces apoptosis and mediates the effects of transforming growth factor-betal on programmed cell death through a p53- and IGF-independent mechanism. J Biol Chem 272: 12181-12188, 1997

9. Hankinson SE, Willett WC, Colditz GA, Hunter DJ, Michaud DS, Deroo B, Rosner B, Speizer FE and Pollak M: Circulating concentrations of insulin-like growth factor I and risk of breast cancer. Lancet 351: 1393-1396, 1998.

10. Chan JM, Stampfer MJ, Giovannucci E, Gann PH, Ma J, Wilkinson P, Hennekens CH and Pollak M: Plasma insulin-like growth factor-I and prostate cancer risk: A prospective study. Science 279: 563-566, 1998.

11. Yu H, Spitz MR, Mistry J, Gu J, Hong WK and Wu X: Plasma levels of insulin-like growth factor-I and lung cancer risk: A case-control study. J Natl Cancer Inst 91: 151-156, 1999.

12. Ma J,Pollak MN, Giovannucci E, Chan JM, Tao Y, Hennekens CH and Stampfer MJ: Prospective study of colorectal cancer risk in men and plasma levels of insulin-like growth factor (IGF)-I and IGF-binding protein-3. J Natl Cancer Inst 91: 620-625, 1999.

13. Chuang ST, Patton KT, Schafernak KT, Papavero V, Lin F Baxter RC, Teh BT and Yang XJ: Over expression of insulin-like growth factor binding protein 3 in clear cell renal cell carcinoma. J Urol 179: 445-449, 2008.

14. Balasenthil S, Broaddus RR and Kumar R: Expression of metastasis-associated protein 1 (MTA1) in benign endometrium and endometrial adenocarcinomas. Hum Pathol 37: 656-661, 2006.

15. Rice TW, Blackstone EH and Rusch VW: 7th edition of the AJCC cancer staging manual: Esophagus and esophagogastric junction. Ann Surg Oncol 17: 1721-1724, 2010.

16. Yang HP, Liu JF, Rao J, Zhang XM, Qian HL, Niu XQ and Zhao ZL: Insulin-like growth factor binding protein-3 (IGFBP-3) genetic variant and the risk of esophageal squamous cell carcinoma in a Chinese population. Genet Mol Res 13 : $4146-4153,2014$

17. Hwa V, Oh Y and Rosenfeld RG: The insulin-like growth factor-binding protein (IGFBP) superfamily. Endocr Rev 20 : 761-787, 1999.

18. Gui Y and Murphy LJ: Insulin-like growth factor (IGF)-binding protein-3 (IGFBP-3) binds to fibronectin (FN): Demonstration of IGF-I/IGFBP-3/fn ternary complexes in human plasma. J Clin Endocrinol Metab 86: 2104-2110, 2001.

19. Yamada PM and Lee KW: Perspectives in mammalian IGFBP-3 biology: Local vs. systemic action. Am J Physiol Cell Physiol 296: C954-C976, 2009.

20. Gill ZP, Perks CM, Newcomb PV and Holly JM: Insulin-like growth factor-binding protein (IGFBP-3) predisposes breast cancer cells to programmed cell death in a non-IGF-dependent manner. J Biol Chem 272: 25602-25607, 1997.

21. Collard TJ, Guy M, Butt AJ, Perks CM, Holly JM, Paraskeva C and Williams AC: Transcriptional upregulation of the insulin-like growth factor binding protein IGFBP-3 by sodium butyrate increases IGF-independent apoptosis in human colonic adenoma-derived epithelial cells. Carcinogenesis 24: 393-401, 2003.

22. Torng PL, Lee YC, Huang CY, Ye JH, Lin YS, Chu YW Huang SC, Cohen P, Wu CW and Lin CT: Insulin-like growth factor binding protein-3 (IGFBP-3) acts as an invasion-metastasis suppressor in ovarian endometrioid carcinoma. Oncogene 27: 2137-2147, 2008

23. Torng PL, Lin CW, Chan MW, Yang HW, Huang SC and Lin CT: Promoter methylation of IGFBP-3 and p53 expression in ovarian endometrioid carcinoma. Mol Cancer 8: 120, 2009.

24. Chang YS, Wang L, Liu D, Mao L, Hong WK, Khuri FR and Lee HY: Correlation between insulin-like growth factor-binding protein-3 promoter methylation and prognosis of patients with stage I non-small cell lung cancer. Clin Cancer Res 8: 3669-3675, 2002.

25. Wang Z, Wang Z, Liang Z, Liu J, Shi W, Bai P, Lin X, Magaye R and Zhao J: Expression and clinical significance of IGF-1, IGFBP-3, and IGFBP-7 in serum and lung cancer tissues from patients with non-small cell lung cancer. Onco Targets Ther 6: $1437-1444,2013$
26. Aishima S, Basaki Y, Oda Y, Kuroda Y, Nishihara Y, Taguchi K, Taketomi A, Maehara Y, Hosoi F, Maruyama Y, et al: High expression of insulin-like growth factor binding protein-3 is correlated with lower portal invasion and better prognosis in human hepatocellular carcinoma. Cancer Sci 97: 1182-1190, 2006.

27. Walker G, MacLeod K, Williams AR, Cameron DA, Smyth JF and Langdon SP: Insulin-like growth factor binding proteins IGFBP3, IGFBP4, and IGFBP5 predict endocrine responsiveness in patients with ovarian cancer. Clin Cancer Res 13: 1438-1444, 2007.

28. Shariat SF, Lamb DJ, Kattan MW, Nguyen C, Kim J, Beck J, Wheeler TM and Slawin KM: Association of preoperative plasma levels of insulin-like growth factor I and insulin-like growth factor binding proteins-2 and -3 with prostate cancer invasion, progression, and metastasis. J Clin Oncol 20: 833-841, 2002.

29. Tas F, Karabulut S, Bilgin E, Tastekin D and Duranyildiz D: Clinical significance of serum insulin-like growth factor-1 (IGF-1) and insulin-like growth factor binding protein-3 (IGFBP-3) in patients with breast cancer. Tumour Biol 35: 9303-9309, 2014

30. Tas F, Karabulut S, Serilmez M, Ciftci R and Duranyildiz D: Clinical significance of serum insulin-like growth factor-1 (IGF-1) and insulin like growth factor binding protein-3 (IGFBP-3) in patients with epithelial ovarian cancer. Tumour Biol 35: 3125-3132, 2014.

31. Seligson DB, Yu H, Tze S, Said J, Pantuck AJ, Cohen P and Lee KW: IGFBP-3 nuclear localization predicts human prostate cancer recurrence. Horm Cancer 4: 12-23, 2013.

32. Kim YH, Sumiyoshi S, Hashimoto S, Masago K, Togashi Y, Sakamori Y, Okuda C, Mio T and Mishima M: Expressions of insulin-like growth factor receptor-1 and insulin-like growth factor binding protein 3 in advanced non-small-cell lung cancer. Clin Lung Cancer 13: 385-390, 2012

33. Rohrmann S, Grote VA, Becker S, Rinaldi S, Tjønneland A, Roswall N, Grønbæk H, Overvad K, Boutron-Ruault MC, Clavel-Chapelon F, et al: Concentrations of IGF-I and IGFBP-3 and pancreatic cancer risk in the European prospective investigation into cancer and nutrition. Br J Cancer 106: 1004-1010, 2012.

34. Firth SM and Baxter RC: Cellular actions of the insulin-like growth factor binding proteins. Endocr Rev 23: 824-854, 2002.

35. Grimberg A: Mechanisms by which IGF-I may promote cancer. Cancer Biol Ther 2: 630-635, 2003.

36. Buckbinder L, Talbott R, Velasco-Miguel S, Takenaka I, Faha B, Seizinger BR and Kley N: Induction of the growth inhibitor IGF-binding protein 3 by p53. Nature 377: 646-649, 1995.

37. Binoux M: Insulin-like growth factor binding proteins (IGFBPs): Physiological and clinical implications. J Pediatr Endocrinol Metab 9 (Suppl 3): S285-S288, 1996.

38. Mehta HH, Gao Q, Galet C, Paharkova V, Wan J, Said J, Sohn JJ, Lawson G, Cohen P, Cobb LJ and Lee KW: IGFBP-3 is a metastasis suppression gene in prostate cancer. Cancer Res 71: 5154-5163, 2011

39. Zhao L, He L, Zhang R, Cai MY, Liao YJ, Qian D, Xi M, Zeng YX, Xie D and Liu MZ: Low expression of IGFBP-3 predicts poor prognosis in patients with esophageal squamous cell carcinoma. Med Oncol 29: 2669-2676, 2012.

40. Jenkins PJ, Khalaf S, Ogunkolade W, McCarthy K, David T, Hands RE, Davies D and Bustin SA: Differential expression of IGF-binding protein-3 in normal and malignant colon and its influence on apoptosis. Endocr Relat Cancer 12: 891-901, 2005.

41. Toh Y, Pencil SD and Nicolson GL: A novel candidate metastasis-associated gene, mta1, differentially expressed in highly metastatic mammary adenocarcinoma cell lines. cDNA cloning, expression, and protein analyses. J Biol Chem 269: 22958-22963, 1994.

42. Cui Q, Takiguchi S, Matsusue K, Toh Y and Yoshida MA: Assignment of the human metastasis-associated gene 1 (MTA1) to human chromosome band 14q32.3 by fluorescence in situ hybridization. Cytogenet Cell Genet 93: 139-140, 2001.

43. Roy S, Packman K, Jeffrey R and Tenniswood M: Histone deacetylase inhibitors differentially stabilize acetylated p53 and induce cell cycle arrest or apoptosis in prostate cancer cells. Cell Death Differ 12: 482-491, 2005.

44. Hofer MD, Menke A, Genze F, Gierschik P and Giehl K: Expression of MTA1 promotes motility and invasiveness of PANC-1 pancreatic carcinoma cells. Br J Cancer 90: 455-462, 2004. 